\title{
Tessituras do excesso: notas iniciais sobre o conceito e suas implicações tomando por base um Procedimento operacional padrão
}

////////////////// Mariana Baltar ${ }^{1}$ 


\section{Resumo}

Este artigo pretende cercar conceitualmente a categoria do excesso, em seus aspectos estilísticos e culturais, bem como suas implicações para o cinema e para o audiovisual. Articulamos o excesso às estratégias de engajamento e de afetação operacionadas por distintos gêneros e obras. Nesse sentido, o conceito é articulado em torno do que entendemos como pedagogia das sensações (fundamental na consolidação e no adensamento do projeto de modernidade) e correlacionado aos chamados gêneros do corpo. A título de exemplo, partiremos dos comentários analíticos sobre o filme Procedimento operacional padrão (Errol Morris, 2008).

\section{Palavras-chave}

Excesso, gêneros do corpo, engajamento afetivo-passional.

\section{Abstract}

This article intends to conceptualize excess as both stylistic element and cultural matrix, establishing its implications for cinematic and audiovisual culture. Excess is here articulated with some affective engagement strategies that are constructed by different genres and oeuvres. Therefore, the concept is related to what we define as a sensational pedagogy (central to the crystallization and strengthening of the modernity project) and to the body genres. In order to grasp the concept, we will focus on the film Standard operating procedure (Errol Morris, 2008).

Excess, body genres, affective and passional engagement. 
2. Este artigo procura sistematizar os primeiros resultados do mergulho teórico nos gêneros vinculados às narrativas de excesso empreendido no âmbito do Nex

(Núcleo de Estudos do Excesso nas Narrativas Audiovisuais) e da pesquisa "Pedagogia das sensações:

o excesso e suas reapropriações na cultura audiovisual contemporânea", desenvolvida com verbas da Faperj (Fundação de Amparo à Pesquisa do Estado do Rio de Janeiro), através do auxílio instalação. Ele não pretende esgotar o assunto, mas delinear o conceito de excesso e suas implicações narrativas e culturais. Trata-se, assim, de um artigo de natureza privilegiadamente teórica, mas que se construiu amparado nas análises de narrativas audiovisuais desenvolvidas nas salas de aula, sobretudo nas disciplinas do que ficou conhecido como a trilogia das sensações, dedicadas ao melodrama, à pornografia e ao horror (a cujos alunos agradeço imensamente).

\section{Excesso como conceito ${ }^{2}$}

No centro do quadro, a luz desenha um círculo em meio à escuridão. Nele, um homem nu, coberto com o que parece ser sua cueca, está a contorcer-se, sentado no chão molhado. O som grave da trilha sonora mistura-se à voz off do personagem, que reconta o episódio encenado. O "Lobo", prisioneiro capturado em Abu Ghraib, está sendo interrogado por duas agentes militares que servem na prisão iraquiana agora sob o controle dos norte-americanos. No canto do quadro, veem-se um par de pernas e um coturno militar. Corte seco - temperado por uma batida de tambor - para um primeiro plano do corpo do torturado refletido na água. Em slow motion, o coturno anda à frente do rosto atônito do rapaz. Em outra cena, logo adiante (em torno de 29 minutos do filme), um primeiríssimo plano na altura do chão nos coloca frente a frente com o sujeito capturado da cena anterior, arrastando-se, ainda nu, no concreto da cela. Ruídos de portas batendo ambientam a sequência.

Trata-se da primeira reencenação (reenactment) do documentário Procedimento operacional padrão (Standard operating procedure) ${ }^{3}$, dirigido por Errol Morris em 2008, e, conforme vou argumentar no presente artigo ${ }^{4}$, é, sem dúvida, um excesso. Dizer isso é apontar não uma "falha" na economia narrativa do documentário, mas um procedimento, estético e político, de incorporação dialógica de marcas estilísticas de gêneros narrativos que se estruturam com base no modo de excesso 5 . 
3. O filme se centra nos agentes que serviam na prisão de Abu Ghraib para trazer a público, a partir de suas falas e de suas fotos, os casos de tortura e abuso praticados pelos militares norteamericanos contra os presos de guerra em 2003, cujas imagens foram amplamente difundidas na internet e depois figuraram nas paredes das galerias do museu Warhol, de Pittsburgh, e do Centro Internacional de Fotografia de Nova

York. Tais imagens expuseram de modo brutal a realidade política de

uma guerra que, naquela época, ainda encontrava inacreditáveis defensores perante a opinião pública.

O filme reconta o caso a partir dos agentes, reiterando o tom de crítica condenatória do que foi considerado,

no julgamento militar, como "procedimento operacional padrão". Neste artigo, foco minha abordagem nas reencenações das fotografias das torturas e dos abusos.

4. Uma primeira versão desse artigo foi apresentada ao Grupo de Trabalho Estudos de Cinema, Fotografia e Audiovisual, do XXI Encontro da Associação Nacional dos Programas de Pós-Graduação em Comunicação, ocorrido na Universidade Federal de Juiz de Fora, em junho de 2012. Agradeço aos colegas do GT pelas leituras e pelos questionamentos que tanto contribuíram para a atual versão, ampliada e revista, do texto.
Correlacionar obras como as de Morris com o excesso, e de certo modo, com a matriz popular, não é uma abordagem totalmente original em relação ao seu cinema. Algo já se falou sobre tal diálogo com a cultura massiva e sobre o papel sensacionalista de suas reencenações, e o diretor pouco esconde suas inspirações. Em mais de uma entrevista, declarou que foi tão influenciado pelos mestres de Hollywood, como Douglas Sirk e Billy Wilder, quanto por documentaristas como Fred Wiseman (GRUNDMANN, 2000), e é justamente porque seu "trabalho mistura as inovações do experimentalismo com o imperativo populista da cultura tabloide" (NUNN, 2004, p. 413) que tomo um de seus filmes como nota visual exemplificadora para as considerações teóricas que aqui traço sobre o conceito de excesso e sua presença no cinema e no audiovisual.

O excesso é a marca comum que leva a pesquisadora de cinema Linda Williams (2004) a definir determinados gêneros como gêneros do corpo, pois mobilizam um convite ao seu público a reagir sensória e sentimentalmente (e, mais especificamente, com o corpo). Tal “convite” é articulado na narrativa através do excesso tomado como sistema primordial das estratégias de representação e expressão.

O termo "gêneros do corpo" é na verdade uma formulação de Carol Clover para o tipo de relação que se estabelece entre obra e público no gênero do horror e no da pornografia. Williams o toma emprestado e o amplia para incluir também o melodrama, pois entende que a mobilização característica desse gênero é uma dupla articulação do excesso em termos de êxtase e de espetáculo. Assim, embora não exclua a possibilidade de outros gêneros também serem pensados como "do corpo" (como o musical e certo tipo de comédia), Williams, em artigo de 1991, põe-se a trabalhar os aspectos estilísticos e políticos desse elemento, usado de modo estruturante, comum aos três gêneros.

Em outro escrito anterior, dedicado mais especificamente ao universo pornográfico, Williams (1989) identifica a capacidade dessas narrativas de mobilizarem uma "reação corporal automática" exatamente pelo fator excessivo. A autora desenvolve a ideia de que 
5. Há outros pontos importantes sobre essa sequência em particular, concernentes à questão moral e de gênero, pois, segundo narram os personagens, o que motivou a tortura dos prisioneiros desse modo específico (com tantas alusões sexuais) foi, para além de serem prisioneiros de guerra, o fato de supostamente terem violado um rapaz de 16 anos. Não estou focando nesse ponto, embora ele indique um caminho de reflexão política fundamental, dado os limites e os propósitos mais específicos do artigo. essas narrativas ganham uma nova vida a partir do que ela define como "frenesi do visível". Resumidamente, o argumento é: com o contexto de cristalização de uma cultura visual desde o século XIX e ao longo do XX, que culminou na consolidação do cinema como invenção moderna, a associação entre visibilidade/visualidade (dar a ver a realidade do mundo) e experiência maquínica instaurou um desejo de ver cada vez mais a "concretude" da realidade do outro (sujeito e mundo). Se tal associação é "fundante" da experiência moderna como um todo (dos discursos espetaculares aos discursos científicos), ela torna-se ainda mais determinante quando investida de uma retórica reiterativa e saturante que busca transformar "tudo" em imagens, não apenas corpos em ação mas também emoções e valores corporificados.

Assim, seguindo a pista dada por Williams e outros autores, com destaque para Singer (2001), percebe-se que a visualidade espetacular e reiterativa é fundamental para a retórica do excesso. Especialmente a expressão do corpo como foco primordial das máquinas do visível, encarnando assim o fascínio, o maravilhamento e a vontade de saber que despertam. Os gêneros do corpo relacionam-se primeiramente ao corpo dado a ver como espetáculo e como ancoragem de uma experiência "extasiástica", como atração. É fundamental entender que é o corpo colocado em ação, em movimentos que "performam" e expressam estados sensoriais e sentimentais que, dado a ver audiovisualmente, inspiram no espectador, se não os mesmos estados, algo bem próximo deles. Convidam, afinal, a fluir e a fruir sensorial e sentimentalmente. Os corpos se movem e mobilizam, como coloca Williams (2004, p. 730): "the moved and the moving". A autora ressalta a importância do compartilhamento das sensações e das emoções possibilitado guiado - pelo encontro “obra e público”.

$\mathrm{Na}$ minha apropriação das reflexões de Williams, argumento que tal compartilhamento responde a uma necessidade primordial do projeto de modernidade, primordial para a própria construção da ideia de sujeito moderno: as necessidades de personalizar as práticas de consumo em projeções empáticas identificatórias: 
Os modos de organização da narrativa em torno do excessivo talvez sejam as maneiras mais eficazes de fazer o público fluir e fruir com a narrativa. Tais idéias - fluir e fruir - são fundamentais na construção da subjetividade moderna. É central, nesse contexto, a dimensão espetacular para alimentar os desejos de circulação e consumo do sujeito moderno (BALTAR, 2007, p. 92).

Nesse sentido, o "modo de excesso" é pensado como as específicas articulações da narrativa, de maneira que seja possível mobilizar reações sensoriais e sentimentais da plateia. Nessa direção, funciona, por exemplo, a ideia da reiteração constante das instâncias da narrativa, como se cada elemento da encenação - desde a música, a atuação, os textos, a visualidade, as performances - estivesse direcionado para uma mesma função; ou seja, como se todas as instâncias dissessem, expressassem o mesmo. A expressão visual está, assim, a serviço de uma obviedade estratégica que toma corpo de maneira exuberante e espetacular e no imperativo de "mostrar" e "dizer" tudo ao longo da narrativa, estabelecendo uma estratégica relação com a obviedade.

A noção de obviedade deve ser entendida aqui não como um elemento pejorativo, mas como um regime de expressividade que tem papel importante no movimento pedagógico das narrativas de excesso, justamente porque trazem em si a marca de uma economia reiterativa (desenvolveremos especificamente essa questão mais adiante) e, com ela, a "facilitação" do engajamento entre obra e público. Engajar-se na narrativa pressupõe colocar-se em estado de "suspensão", ou seja, encontrar-se sentimental e sensorialmente vinculado a ela. Para catalisar esse convite ao engajamento, o apelo ao visual (ao narrar a partir de imagens que se estruturam como símbolos) é elemento fundamental.

Não por acaso, esses gêneros formaram as bases da tradição de um cinema popular e massivo que encontra parte de seu apelo e sucesso na capacidade de traduzir a complexa e ambivalente realidade em "imagens" de pronta identificação e intensa afetação e engajamento. 
6. Em sua Filosogia do horror,

Carroll faz uma interessante

apropriação das reflexões da antropóloga Mary Douglas a partir do livro Pureza e perigo, mostrando como a construção sociocultural das noções de higiene (associada a uma ideia de civilidade etnocêntrica) informa a expressão narrativa dos sentimentos de medo e repulsa característicos do gênero.

7. A noção de atrações vem, é claro, da formulação "cinema de atrações", de Tom Gunning e André Gaudreault. Quando correlaciono tal reflexão ao domínio

da pornografia, sobretudo em sua face contemporânea, a partir da disseminação das tecnologias

do vídeo e de suas formas de estruturação e consumo na internet, não quero meramente opor narrativa e atrações. Tal seria um contrassenso, inclusive em relação às teorizações

dos autores. Quero chamar a atenção aqui para o fato de que há uma diferença na organização do modo de excesso no interior da pornografia e que tal diferença se dá no âmbito da narrativa (entendendose esta última em sua acepção mais

restrita de storytelling). Isso fica claro se percebermos as mudanças no gênero da pornografia hardcore clássica (aquela institucionalizada nos anos 1970) e a lógica cada vez mais gore de esquetes de atos sexuais

que podem (quase devem) ser consumidos de modo fragmentário, e não sequencial, algo que Susanna

Paasonen define como mais da ordem do showing que da ordem do
No universo melodramático, por exemplo, o apelo à simbolização e à obviedade se dá no limite da ação. Os valores devem ser mostrados de maneira exemplar, corporificados (em personagens e/ou objetos) - a virtude e a vilania, o bem e o mal - , e, por isso, são apresentados nas ações dos personagens colocados em situações de limite, ações estas que devem estar submetidas a um olhar público presentificado claramente na narrativa. Dessa maneira, sob o julgo desse olhar público, processa-se, com mais intensidade, todo um convite ao engajamento através da mobilização de sentimentos de compaixão e comoção.

No caso do horror, a obviedade parece à primeira vista mais problemática, uma vez que uma das vertentes mais importantes do gênero o liga a certo suspense e mistério. Contudo, para construir as sensações desse mistério, as narrativas lançam mão de simbolizações de fácil identificação e de forte apelo visual e sonoro, recuperando repertórios cristalizados no imaginário sócio-histórico e reatualizando, no nível da obviedade, os clichês do próprio gênero. A localização da fonte do medo e da repulsa é claramente delineada no corpo monstruoso e naquilo que Carroll (1999) conceitua como metonímia do horror, em que a construção espacial (becos escuros e sujos onde o "mal" habita) agrega valor de monstruosidade ao personagem ${ }^{6}$. Afinal, a construção do monstro deve se dar de modo espetacular para, com isso, posicionar os valores morais, uma vez que “o monstro é algo ou alguém para ser mostrado (monstrare), servindo ao propósito de revelar o produto do vício e da desrazão como um aviso (monere)" (MAGALHÃES, 2003 , p. 25). Por isso, a iconografia recorrente do gênero investe em closes de fluidos, em especial corpóreos, enquadrados sob uma luz densa que privilegia as sombras e a escuridão.

No universo da pornografia, tais marcas de obviedade e simbolização se apresentam de modo um tanto diverso pelas próprias características do gênero, que, cada vez mais, prescinde de uma estrutura narrativa clássica em favor de uma lógica mais forte de atrações ${ }^{7}$. Nela, a obviedade central ao modo de excesso se fará presente no imperativo da visibilidade que reorganiza o repertório do erotismo como explicitação, intensificando o que Linda 
narrative (cf.: PAASONEN, 2010). Claro está que há uma dimensão de moldura narrativa nesses atos - assim como há uma dimensão de moldura narrativa no cinema de atrações - , mas se trata de uma outra ordem de experiência frente ao discurso fílmico. Explicar com mais propriedade tais questões implicaria um mergulho no universo pornográfico que explodiria os limites desse artigo.
Williams (1989) qualifica em seu livro sobre o gênero de o "frenezi do visível". Dentro dessa lógica de atrações, os procedimentos de simbolização exacerbada se processam como deixas que fornecem uma moldura narrativa - e com isso um certo modo de olhar - às atrações e aos esquetes sexuais explicitados.

O modo de excesso torna-se a base de estruturação das narrativas institucionalizadas em gêneros, tais como os gêneros do corpo, mas não é exclusivo deles, uma vez que, argumento, apontam para uma sensibilidade geral que clama por uma lógica personalista e de valorização secular dos bens e dos objetos e respondem por essa sensibilidade. Uma lógica que se alinha perfeitamente às transformações da modernidade e à construção de uma sociedade laica e de mercado.

Argumento análogo faz autores como Peter Brooks (1995), Thomas Elsaesser (1987), Ben Singer (2001), Ismail Xavier (2003) e Jesús Martín-Barbero (2001). Todos, de uma maneira ou de outra, reconhecem o valor do excesso em primeiro lugar como elemento narrativo, mas que, enquanto tal, aponta para um modo de percepção de mundo, na regulamentação de uma sociabilidade relacionada ao contexto pós-sagrado que se instaura e se adensa a partir da modernidade.

Nesse sentido, o excesso pode ser abordado de dois modos correlacionados: como estratégia estética e como matriz cultural popular e massiva - sobre esse conceito, conferir teorização de Jesús Martín-Barbero (2001), de Mikhail Bakhtin (1996) e de Ana Enne (2007 e 2006), entre outros. Não desenvolverei especificamente as implicações dessa afirmação aqui, mas é preciso ressaltar que ela me parece ser uma das bases teóricas para a consolidação da cultura midiática contemporânea, de maneira geral (sustentada na dimensão espetacular), e para o sensacionalismo midiático do século XX, de maneira mais específica. Contudo, é importante ressaltar que o excesso não é um elemento restrito ao fluxo do sensacional e do espetáculo midiático.

Conforme estamos argumentando, a construção de uma expressividade visual forte é uma das características fundamentais da matriz do excesso, elemento que se consolida como estratégico 
8. A ideia de uma pedagogia das sensações surge a partir dos diálogos com a professora doutora Ana Lucia Enne, que, com a professora doutora Marialva Barbosa, trabalhava

o universo do sensacionalismo (pensando-o como inserido no fluxo do sensacional, ou seja, vinculado à matriz cultural popular). Ambas enfatizam o processo cultural e o fluxo do sensacional (no caso de Barbosa, vinculando-o ao universo da imprensa, sobretudo) e seguem desenvolvendo a noção de modo separado em suas pesquisas, que se constituem grandes referências

e somam-se à maneira como desenvolvo a ideia da pedagogia das sensações associada ao conceito de gêneros do corpo de Linda Williams e focada, mais particularmente, nas narrativas audiovisuais. Agradeço imensamente a ambas pelos diálogos e em especial a Ana Enne pela interlocução e pela parceria cotidiana na UFF. para a articulação de uma pedagogia das sensações ${ }^{8}$, que se configura em resposta à sensibilidade geral forjada no contexto de formação da subjetividade moderna.

Tal sentido pedagógico se afirma em dois movimentos: de um lado, o "ensinamento" através de um regime que privilegia o envolvimento sensório-sentimental e, de outro, um sentido de pedagogia que por vezes se confunde com domesticação/ naturalização do lugar das sensações e dos sentimentos na experiência da modernidade.

O excesso é entendido como a estratégia principal de "pedagogização" através da ativação de um saber sensóriosentimental eficaz enquanto agente da percepção e da experiência da realidade. Tal saber é parte tão importante da construção da consciência e das subjetividades modernas quanto o racionalismo cientificista que é comumente associado aos séculos de desenvolvimento da modernidade.

Ao traçar inicialmente o conceito de pedagogia das sensações, Ana Lucia Enne e Mariana Baltar ressaltam que:

\begin{abstract}
as narrativas veiculadas através desses meios, também herdeiras de processos anteriores, pois que imersas num fluxo do imaginário que atravessa a história ocidental, vão desempenhar um papel central em termos de uma pedagogia das sensações, dando conta da ambigüidade desta modernidade, na qual o racionalismo se impõe como a verdade em detrimento da emoção, sem, contudo, ser capaz de eliminá-la, pois que, dialeticamente, tal ambigüidade é constitutiva da própria existência do ser (ENNE; BALTAR, 2006).
\end{abstract}

Fazendo eco à tese de outros pesquisadores, notadamente Thomas Elsaesser (1987), Peter Brooks (1995) pensa o modo de excesso como o elemento estruturante de mobilização, no interior das instâncias narrativas, de educação de uma "verdade" no contexto do mundo pós-sagrado - "verdade” essa, do sujeito e do mundo, que será vinculada ao universo da moralidade. 
Tomando o melodrama teatral como ponto de partida para estabelecer as características estéticas do excesso (que o autor vai identificar como uma estética do astonishment), Brooks reconhece que os modos envolventes, expressivos e simbólicos de apresentar modelos, a serem seguidos ou rechaçados, de virtude e vilania, de bem e mal são articulados em uma pedagogia moralizante.

O diferencial está no fato de essa pedagogia moralizante se fazer eficaz pelo engajamento sensório e sentimental - pela dinâmica de mobilização entre público e narrativa. É nesse sentido que noções como as de arrebatamento, sedução, estímulos e reações sentimentais e sensoriais tornam-se importantes elementos da pedagogia das sensações. Estímulos e reações catalisados pelo excesso presente na materialidade da narrativa que faz ligar, de algum modo, obras e gêneros tão distintos como o melodrama teatral, suas vertentes cinematográfica e televisiva, às obras literárias que vão do folhetim clássico aos escritos de Balzac e Henry James, apenas para citar alguns exemplos elencados por Brooks.

Reflexão análoga faz Beatriz Sarlo (2000) quando analisa o papel das novelas sentimentais semanais no contexto de modernização da Argentina, entre os anos de 1917 e 1927. A autora mostra como tais novelas mobilizam, a partir de estratégias de apelo melodramático e erótico, uma relação de engajamento com seu público que participou ativamente na "pedagogização" da vida amorosa e dos padrões familiares das classes trabalhadoras da periferia de Buenos Aires. Tais narrativas "desenham um vasto, porém monotônico império dos sentimentos organizado segundo três ordens: a dos desejos, a da sociedade e a da moral" (SARLO, 2000, p. 22). E assim o fazem a partir do que a autora identifica como o "prazer da repetição, do reconhecimento, do trabalho com matrizes já conhecidas" (SARLO, 2000, p. 23).

O que Sarlo aponta, portanto, é a possibilidade de pensar as narrativas sensacionais como esfera de ensinamento sobre o mundo, um ensinamento que se dá através do prazer sentimental do reconhecimento. Um caminho para mobilizar, narrativamente, tal prazer é tecer a obra numa economia reiterativa, ou seja, num modo de excesso. De um lado, 
“cristalizando" a experiência da modernidade a partir das sensações, mobilizando os estímulos (SINGER, 2001), e, de outro, "domesticando" o lugar do sensacional, vinculando, moralmente, o fluxo das sensações a determinados padrões de conduta (e nesse sentido, é claro, bastante coerente com o tão apontado projeto moralizador dos "gêneros do corpo").

Para além de reconhecer esse importante papel pedagógico na cristalização do projeto de modernidade (e ainda presente em um cenário de hipermodernidade), quero chamar a atenção para o fato de que a eficácia desse papel reside no engajamento passional/afetivo que é mobilizado, justamente, pela tessitura do excesso. Tessitura essa que encontra nas narrativas audiovisuais seu formato mais bem acabado, dada a própria natureza visual e sensorial da imagem e do som.

9. É fundamental notar que reiteração não é mera repetição, mas representa a insistência de dizer o mesmo a partir de distintos elementos. Tal insistência, no interior de uma narrativa, tenta fazer convergir, por exemplo, todos os planos simbólicos da tessitura da narrativa para uma

mesma e coesa significação, construindo e garantindo, assim, a coerência interna e facilitando a "comunicabilidade". Encontramos tal lógica reiterativa na matriz do cinema clássico narrativo, mas não se trata de uma exclusividade dele.

\section{Entre o espetáculo e o êxtase, entre a narrativa e as atrações}

Dito de um modo mais direto, o excesso é um elemento estilístico que se vincula sobretudo (ainda que não exclusivamente) a uma matriz cultural "fundante" da subjetividade moderna. Nesse sentido, sua eficácia se dá na reiteração ${ }^{9}$ de símbolos que presentificam a experiência da realidade e os valores morais - a "moral oculta", para usar uma noção presente em Peter Brooks (1995) que diz respeito à "superdramatização" da realidade.

Em recente livro, em que procura refletir sobre as listas, Umberto Eco (2010) dedica dois capítulos ao excesso, associando-o de modo peculiar ao "listar". Se, de maneira geral, argumenta o autor, o ato de listar usualmente responde ao impulso organizador, classificatório, condensador, há outro uso que indica um caminho bastante diverso, que se afasta do desejo de dar forma em direção ao "gosto de deformar" (ECO, 2010, p. 245). Não por acaso, Eco localiza esse outro uso, identificado por ele com o excesso, a partir do contexto rabelaisiano do Renascimento e com forte impacto na modernidade: “é o início de uma poética da lista pela lista, redigida por amor à lista, da lista por excesso" (ECO, 2010, p. 250, grifo do autor). 
Assim, há um listar/elencar que indica o sabor do excesso e da saturação. O melhor exemplo desse movimento está, sem dúvida, nas longas listas em Rabelais, nas quais sem número de palavras dizem rigorosamente o mesmo e, ao dizê-lo de modo reiterativo, provocam no leitor um estado sensorial de riso e afogamento. Estado de arrebatamento e vertigem que se consegue pelo "amor ao excesso", não se cansa de repetir Eco em múltiplos exemplos, que vão de Bosch a Hugo:

10. A obviedade e a simbolização exacerbada são duas das três categorias que identificam o universo do melodrama e dizem respeito a procedimentos de presentificação e sumarização de sensações e sentimentos no interior das narrativas, enquadrando, através de metáforas de forte apelo visual, os dilemas morais e sentimentais do enredo (BALTAR, 2007). Outra

categoria seria a antecipação.

Estamos ampliando o uso dessas categorias para outros gêneros, pois entendemos que elas se vinculam diretamente à matriz do excesso comum a narrativas que colocam em uso ou em diálogo tal elemento estilístico estruturante.

11. Trata-se dos artigos "The cinema of attractions: early film, its spectator and the avant-garde", de Tom Gunning, publicado em Wide Angle, e "Le cinéma des premiers temps: un défi à l'histoire du cinéma?", de André Gaudreault e Tom Gunning, publicado no periódico japonês Gendai Shiso: revue de la pensée d'aujourd'hui.

\begin{abstract}
obviamente, não há razão para elencar tantas e tão inauditas formas de limpar o próprio traseiro, tantas adjetivações do membro viril, tantos modos de esganar os inimigos ou tantos jogos que Gargântua sabia jogar (ECO, 2010, p. 249).
\end{abstract}

Eco reconhece então duas tendências que para ele informam parte da história da literatura moderna e pós-moderna: lista por reiteração (que o autor identifica com um excesso coerente, em que os itens da lista convergem para um mesmo campo de significação) e lista por enumeração caótica, que indica uma "reunião de coisas voluntariamente desprovidas de relações recíprocas" (ECO, 2010, p. 254), o que, para mim, poderia ser identificado com uma saturação de elementos. Assim, reiteração e saturação são procedimentos diferentes ligados ao excesso.

Alargando a reflexão de Eco para o universo audiovisual, em cotejo com os pensadores do excesso como estilística do cinema, argumento que os procedimentos de reiteração e saturação apontam para comportamentos estéticos diferentes, nos quais um parece conduzir todos os elementos que compõem a tessitura do discurso fílmico para um mesmo ponto de convergência (por exemplo, através dos usos da obviedade da simbolização exacerbada ${ }^{10}$ ), e o outro faz uso intenso da vertigem associativa de ideias que caracteriza o que Tom Gunning e André Gaudreault identificaram com o conceito de atração.

O conceito nasceu no contexto dos estudos sobre o primeiro cinema e foi formulado em dois ensaios fundadores de $1986^{11}$ 
12. É interessante notar, conforme lembra em seu ensaio-memória sobre a formulação do conceito, que Gunning estava envolvido no início dos anos 1980 com estudos de gêneros narrativos, em especial

o melodrama e o cinema noir, buscando pensar os diferentes modos de envolvimento e de afetação do espectador mobilizados por tais gêneros (GUNNING, 2006).

13. “claramente, em um certo sentido, os espetáculos cinematográficos recentes têm

reafirmado suas raízes nos estímulos e nos carnival rides, naquilo que poderia ser chamado de um cinema de efeitos à la Spielberg-Lucas-Coppola."

14. Nesse sentido, vale lembrar as formulações de Kristin Thompson sobre o excesso em seu texto, de 1981, "The concept of cinematic excess" (2004). Nele, a autora associa o excesso ao conceito de sentido obtuso de Roland Barthes, como "algo [que] não tem função

para além da oferecer-se ao jogo perceptivo" (THOMPSON, 2004, p.

:516) e, nesse sentido, que contraria

a motivação realista. A autora define quatro formas em que essa contrariedade se dá (1. disjunção na forma estilística; 2. na duração da tomada; 3. na reiteração; e 4. na

repetição) e, como conclusão, as correlaciona à formulação brechtiana

de estranhamento. No meu entender, ao opor mais fortemente o excesso à motivação realista e à acerca de um cinema de atrações, cuja noção foi inspirada no conceito de montagem de atrações de Eisenstein, formulado em 1923. Conforme lembra Jacques Aumont (1987), o termo tinha, já nos escritos do pensador russo, três concepções correlacionadas: a dimensão de performance, a associação de ideias e a capacidade de provocar agitação (excitação) do espectador.

Foram exatamente essas concepções que inspiraram a apropriação de Gunning do conceito de atração. De saída, o autor americano atesta a necessidade de refletir sobre o cinema de atrações para além do marco histórico do primeiro cinema, enfatizando, também como Eisenstein, o fato de que uma atração deve produzir no espectador “choques emocionais”. Gunning ressalta tal questão ao correlacionar a ideia de atração com algo além do simples processo de apelar ao gosto popular. Há para ele uma dimensão agressiva com a atração, e é por tal dimensão que o autor expande o conceito para correlacioná-lo com as vanguardas dos anos de 1920 e 1960. Mas não é apenas à vanguarda que a atração diz respeito. $\mathrm{Na}$ versão revista do artigo ${ }^{12}$, de 1990, Gunning (2006, p. 387) afirma que "clearly in some sense recent spectacle cinema has reaffirmed its roots in stimulus and carnival rides, in what might be called the Spielberg-Lucas-Coppola cinema of effects"13.

Um cinema de efeitos incorpora, no interior da tradição narrativa comercial e espetacular, a dimensão das atrações, confirmando a possibilidade e a necessidade de ultrapassar a mera oposição entre o cinema de atrações e o sistema narrativo. Interessado em um ponto análogo, Scott Bukatman (2006) busca superar a oposição a partir da aproximação entre os conceitos de atrações e de prazer visual de Laura Mulvey. Bukatman tece então seus argumentos a partir do que para ele há em comum entre os conceitos: a força espetacular, disruptiva e vulcânica (os termos são dele) de ambos. Para ele, essa força reside no excesso cuja lógica responde à ordem espetacular do instante, a qual, por sua vez, representa um tênue e tenso equilíbrio entre a potência domesticadora da narrativa e o prazer disruptivo e exibicionista (no sentido da possibilidade de dar e dar-se a ver) da atração ${ }^{14}$. 
própria tradição narratica clássica, a autora restringe demais o conceito e esquece a presença intensa e estruturante desse elemento no interior do sistema narrativo clássico. Alongar-me nesse debate, por mais importante que seja, me forçaria a ultrapassar os limites do artigo.

15. É importante não entender essa leve decomposição do excesso em dois elementos distintos - e ao mesmo tempo tão intensamente entrelaçados - como uma oposição entre eles. Se Williams faz questão de separá-los, e aqui sigo e desenvolvo a ideia, é por motivação e necessidade de natureza teórica, a fim de precisar conceitualmente as estratégias e as implicações no interior da narrativa. Mas claro está que muitas das vezes, na concretude dos filmes, espetáculo e êxtase/ reiteração e saturação aparecem amalgamados, conduzindo ao engajamento sensorial e sentimental.

16. "visualmente, cada um desses excessos 'extasiásticos', podemos dizer, compartilhariam a qualidade

do descontrole convulsivo e espásmico - do corpo fora de si [...] sonoramente, os excessos são marcados pelo recurso não às articulações da linguagem, mas às inarticulações dos gemidos de prazer na pornografia, dos gritos de medo no horror, dos soluços de angústia no melodrama". (WILLIAMS, 2004, p. 729).
Essa discussão nos remete de volta ao texto-base de Linda Williams (2004). Nele, a autora entende o excesso como êxtase e espetáculo $^{15}$ investidos na dimensão do corpo como foco da ação e da reação de narrativa/personagens e espectadores. Ou seja, da dimensão do corpo como vetor espetacular e atrativo (mais notadamente no corpo feminino, visto que parte do diálogo teórico de Williams se dá em cotejo com os gender studies).

Para ela, a dimensão espetacular está associada ao espetáculo do corpo capturado no ato da sensação ou da emoção; nesse sentido, é fundamental mostrar o gozo, o medo, o choro, privilegiadamente através de uma forma expressiva intensamente associada às noções de proximidade e intimidade: o close-up.

Já a ordem do êxtase engloba o corpo como fonte de estímulo e excitação:

$$
\begin{aligned}
& \text { visually, each of these ecstatic excesses could be said to } \\
& \text { share a quality of uncontrollable convulsion or spam } \\
& \text { - of the body "beside itself" [...]. Aurally, excesses is } \\
& \text { marked by recourse not to the coded articulations of } \\
& \text { language but to inarticulate cries of pleasure in porn, } \\
& \text { screams of fear in horror, sobs of anguish in melodrama } \\
& \text { (WILLIAMS, 2004, p. } 729)^{16} \text {. }
\end{aligned}
$$

Ao ressaltar a dimensão espásmica do corpo (como vetor da ação e como convite à semelhante reação do espectador) - o corpo fora de si (beside itself) - e associar tal dimensão aos procedimentos imagéticos e sonoros (mobilizando a sensorialidade através dos ruídos), Williams aponta, no fundo, a potencialidade saturante do uso de elementos audiovisuais para além da função de narração (storytelling). Aponta ainda como tal dimensão, por sua condição de superenvolvimento (over-involvement) em sensações e emoções, contribui justamente para a eficácia da narrativa.

No seu uso mais comum nas tradições dos gêneros do corpo, o excesso conduz a vínculos empáticos configurados muito frequentemente, mas não exclusivamente, em temáticas que envolvem instâncias moralizantes, que serão articuladas de maneira 
exacerbada e caracterizadas pelo predomínio da visibilidade (reiterando imagens de fácil apreensão, ainda que em discursos verbais) que se articula em um sistema de simbolização exacerbada. Argumento, a partir da reflexão de Williams, que tal uso indicaria a dimensão espetacular do excesso, que, cotejando com as ideias de Eco, apontaria para estratégias e desejos reiterativos.

Mas há ainda outra dimensão (que não passa totalmente desapercebida por Williams, embora não seja o foco de seu artigo) que ocorre de modo mais próximo das atrações, em que o excesso aparece como inserts de choque e saturação. Quero argumentar que tais inserts podem se desenvolver de, ao menos, dois modos:

1. Como incorporação alusiva das tradições narrativas do modo de excesso (os gêneros do corpo em si), com intuito de exacerbar a experiência sensorial.

2. Como inserção/associação “extasiástica”, saturada e vertiginosa de imagens e sons.

Se quisermos diferenciar um procedimento do outro (considerando, é claro, que não se trata de uma oposição, visto que ambos podem ocorrer no interior de um mesmo discurso fílmico), proponho chamar um de excesso narrativo e outro de excesso de atrações. Argumento, reafirmando a dimensão circular e não dicotômica de ambos os "excessos", que as reencenações ao longo do filme de Morris - que aqui tomo como detonador ilustrativo dessas notas teóricas - são inserts de excesso de uma dupla ordem: de um lado, reinstauram a dimensão do sistema narrativo no interior do documentário; de outro, produzem apropriações alusivas dos gêneros do corpo (mais particularmente do horror) para saturar, na ordem das atrações, sua retórica de ordem política.

\section{O Procedimento operacional padrão de Errol Morris como mobilizações de excesso}

O norte-americano Errol Morris faz parte um panorama mais “contemporâneo" do documentário em que é a construção do discurso que se coloca como problema. A materialidade 
fílmica é organizada reflexivamente para borrar ainda mais as fronteiras dos gêneros e das tradições cinematográficas. Pastiche e paródia são elementos comuns para intensificar o questionamento, combinando efeitos estéticos diferenciados tais como fragmentação da narrativa, animações, intervenções e descontinuidades nas imagens e nos sons.

Esse cenário se vê produtivamente presente, segundo analisa Bill Nichols (1993), em um conjunto de filmes políticos de inspiração pós-moderna, com destaque para The thin blue line (1987), de Errol Morris. O autor ressalta em sua análise a maneira como as marcas do documentário clássico são usadas ironicamente no filme para internalizar um questionamento do próprio estatuto do documentário como produção de um sentido verdadeiro e unívoco da realidade e sobre ela. "The thin blue line se priva da aliança que prevalece entre documentário e imagens autênticas" (NICHOLS, 1993, p. 173). Morris consegue tal efeito colocando em uso o que na verdade é uma de suas características marcantes (seu procedimento padrão): o uso de reencenações, estilisticamente marcadas enquanto tais, como modos de questionar o estatuto da evidência e ao mesmo tempo afirmar a verdade de seu discurso fílmico.

No caso específico de Procedimento operacional padrão, tais reencenações atuam como inserts de excesso, identificados estilisticamente pelas alusões, bastante óbvias, ao horror e ao melodrama. Uma das mais impactantes delas (cerca de 40 minutos do filme) reencena a tortura psicológica do prisioneiro conhecido como Gilligan (o homem preso a fios que supostamente estariam ligados a correntes elétricas, que seriam acionadas caso ele dormisse ou baixasse os braços). Chamam a atenção a luz e a trilha sonora, que emulam a fotografia do que alguns teóricos contemporâneos do horror têm identificado como torture porn, para lidar com filmes como Jogos mortais (James Wan, 2004) e O albergue (Eli Roth, 2005) ${ }^{17}$, justamente pelo grafismo das cenas de tortura e violência - grafismo que ao mesmo tempo explicita e excita o centro da ação violenta (excesso em seu estado clássico). Tais cenas compartilham entre si uma 
iluminação marcadamente escura com apenas um foco de luz amarela e densa desenhando o centro da ação do quadro, o corpo do torturado. Essa mesma estrutura está constante e obviamente presente nas reencenações do documentário de Morris.

Todas as reencenações repetem um mesmo padrão, o que é muito importante para serem reconhecidas enquanto tal, enquanto inserts de excesso, diria. Primeiro, elas são antecipadas pelas imagens reais e por depoimentos que recontam tais imagens (muito frequentemente, depoimentos das agentes femininas); uma trilha sonora grave une significativamente a passagem da imagem real/ fotografia still à reencenada, em movimento; a já mencionada luz cria uma relação de contraponto à luz branca, clara e ao setting acéptico das situações de entrevista.

Efeitos de slow motion (sobretudo nos fluidos corporais; por exemplo, uma gota de sangue caindo do nariz acerca de uma hora de filme, quando um dos prisioneiros acaba morto) e ruídos dos menores movimentos do corpo pontualmente adicionados e equalizados de modo a ficarem nitidamente "focalizados" são claramente marcas do excesso, tal como venho delineando, amplamente usadas em todas as cerca de oito reencenações ao longo do documentário.

Essa estrutura meticulosa é central para a economia do filme e para a sua eficácia no convite à "afetação" sensorial e sentimental do espectador. Ela aponta para uma questão fundamental: recobre de legitimidade as cenas tão obviamente reencenadas e assim fornece uma moldura autorizada para o choque do excesso das encenações.

Assim, os inserts são colocados para algo mais complexo do que meramente deslocar o lugar de fala do documentário; eles não almejam questionar o estatuto do real das imagens, mas, através da sua saturação, a partir da afetação sensorial, e por causa dela, bagunçar a tradicional "ordem melodramática de justiça"; questionar, politicamente, o suposto lugar heróico da força militar norte-americana.

A crítica política é óbvia e não se tratava de uma voz original ou isolada - um mesmo questionamento da justificativa moral e política da suposta guerra ao terror já era corrente no ano de 
produção do filme (2008). Basta se lembrar do filme de Michael Moore (2004) ou mesmo de menções condenatórias nos TV shows norte-americanos de maior sucesso, como ER (2006). Contudo, tais críticas resguardavam a figura dos combatentes como heróis inocentes enganados a tomar parte em uma guerra não mais justificável. No filme de Morris, a crítica se volta forte e diretamente a eles, expondo ao cabo a violência como norma, como norma de guerra que é "horrorificamente" naturalizada.

O filme, em sua dimensão melodramática, esforça-se em não generalizar sua condenação e retrata com certa ambivalência alguns dos personagens (agentes militares que serviam em Abu Ghraib). Os sujeitos que recontam os episódios, que olham e explicam as fotos e as ações apresentam-se ao longo do documentário como omissos - mais que responsáveis ativos pelos acontecimentos. Há, contudo, pelo menos um dos personagens que é constantemente construído enquanto vilão: Charles Graner Jr., personagem cuja ausência visível no documentário é altamente significativa (o sargento foi depois sentenciado a dez anos de prisão pela corte marcial que julgou o caso).

De modo coerente com a inspiração e com o lugar cultural de fala melodramático que marca os documentários do diretor (em consonância com o imaginário cultural norte-americano), o filme de Morris certamente posiciona Graner como o grande vilão, mas também não deixa de fazer "espirrar a marca da maldade" para todos os agentes envolvidos. E o faz através dos modos como encena e costura os inserts das reencenações das torturas.

Os inserts - pelo seu regime excessivo e alusivo - fazem dos militares norte-americanos o corpo monstruoso - fonte do medo e da repulsa. Embora tal construção não seja geral e irrestrita (nem todos merecem condenação; alguns, sobretudo as soldadas, são melodramaticamente traçados de modo a serem quase inocentados), ela está visivelmente presente, expressa.

Portanto, o que se coloca como foco de interesse nesse caso é o procedimento pelo qual tal crítica política se apresenta: uma pedagogia das sensações articulada através do excesso e da apropriação das matrizes dos gêneros do corpo (sobretudo, o melodrama e o horror). 


\section{Considerações finais}

Procedimento operacional padrão figura como ilustração das questões de fundo teórico trabalhadas no artigo, mas não como mero pretexto para a teoria. Poderia analisar o filme de Morris a partir de muitas outras abordagens - seu cotejo com o domínio teórico do documentário, seu lugar como peça de uma política espetacularizada, os questionamentos sobre a natureza dos dispositivos imagéticos que a narrativa fílmica e o próprio caso das fotos de Abu Ghraib levantam. Todas as miradas seriam muito pertinentes, e sei que corro o risco de operar uma injustiça analítica. Por outro lado, algo se escreveu a partir de tais recortes (cf. FIGUEIREDO, 2009; NUNN, 2004 ou a conferência proferida por Alice Maurice no Visible Evidence em 2009). Se me aproprio da obra de forma a trabalhá-la como um caso do conceito de excesso é porque o filme opera, como tantos outros, com o tipo de procedimento estético que caracteriza o excesso.

E, mais ainda, o faz de modo a deixar claros dois aspectos importantes que gostaria de ressaltar a partir das notas traçadas aqui. Dois aspectos que atestam a fertilidade do conceito para uma reflexão que se afina com o campo de estudos do afeto, da dimensão sensorial e corpórea do cinema e audiovisual:

1. Coloca em cena o excesso narrativo (trabalhando a partir da reiteração) e o excesso das atrações (estruturando-se em inserts de saturação pelos efeitos de choque alinhavados a partir de um regime alusivo).

2. Acredito que o filme trabalhe na chave de uma política do excesso que recoloca em outro patamar o impulso moralizante da pedagogia das sensações. 
Assim sendo, de alguma maneira, o filme de Morris aponta para as possibilidades de politizar o conceito. De ser possível enxergar o excesso como potência crítica que fale de outro lugar que não o tradicionalmente moralista associado à manutenção da cultura hegemônica. Faz possível pensar a eficácia moralizante do engajamento afetivo sensório-sentimental dissociada das constrições moralistas das tradições dos gêneros do corpo ao longo da modernidade. 
AUMONT, J. Montage Eisenstein (theories of representation and difference). London: BFI; Indiana: Indiana Press, 1987.

BAKHTIN, M. Acultura popularna Idade Média e no Renascimento: o contexto de François Rabelais. São Paulo: Hucitec; /Brasília: UnB, 1996.

BALTAR, M. Realidade lacrimosa: diálogos entre o universo do documentário e a imaginação melodramática. Tese (Doutorado) Niteroi - Universidade Federal Fluminense, 2007.

BARBOSA, M.; ENNE, A. L. "O jornalismo popular, a construção narrativa e o fluxo do sensacional". In: CONGRESSO DA FEDERAÇÃO DAS ASSOCIAÇÕES LUSÓFONAS DE CIÊNCIAS DA COMUNICAÇÃO, 2006, Santiago de Compostela, Espanha, abr. 2006.

BROOKS, P. The melodramatic imagination Balzac, Henry James, melodrama and the mode of excess. New Haven: Yale University Press, 1995.

BUKATMAN, S. "Spectacle, attractions and visual pleasure". In. STRAUVEN, W. (Org). Cinema of attractions reloaded. Amsterdam: Amsterdam University Press, 2006.

CARROLL, N. A filosofia do horror: ou paradoxos do coração. Campinas: Papirus, 1999.

ECO, U. A vertigem das listas. Rio de Janeiro: Record, 2010.

ELSAESSER, T. "Tales of sound and fury. Observations on the family melodrama”. In: GLEDHILL, C. (Org.) Home is where the heart is: studies in melodrama and the woman's film. London: British Film Institute, 1987.

ENNE, A. L. "O sensacionalismo como processo cultural”. EcoPós: publicação da Pós-Graduação em Comunicação e Cultura, v. 10, n. 2, jul.-dez. 2007.

ENNE, A. L.; BALTAR, M. “A construção do fluxo do imaginário sensacionalista através de uma "pedagogia de sensações”. In: REDE ALCAR, 2006, São Luís, Maranhão, jun. 2006. 
FIGUEIREDO, V. F. de. "Novos realismos e o risco da ficção". Revista CMC: comunicação, mídia e consumo, São Paulo, v. 6, n. 16, p. 29-43, jul. 2009.

GOUREVITCH, P.; MORRIS, E. Procedimento operacional padrão: uma história de guerra. São Paulo: Cia. das Letras, 2008.

GRUNDMANN, R. "Truth is not subjective: an interview with Errol Morris". Cineaste, June, v. 22, 2000.

GUNNING, T. "The cinema of attractions: early film, its spectator and the avant-garde". In. STRAUVEN, W. (Org.). Cinema of attractions reloaded. Amsterdam: Amsterdam University Press, 2006.

"Attractions: how they came into the world". In: STRAUVEN, W. (Org.). Cinema of attractions reloaded. Amsterdam: Amsterdam University Press, 2006.

KRISTEVA, J. Powers of horror. Nova York: Columbia University Press, 1982.

MARTÍN-BARBERO, J. Dos meios às mediações: comunicação, cultura e hegemonia. Rio de Janeiro: UFRJ, 2001.

MULVEY, L. Visual and other pleasures: language, discourse, society. Londres: MacMillan, 1989.

NICHOLS, B. "Getting to know you...: knowledge, power and the body”. In: RENOV, M. (Org.). Theorizing documentary. New York: Routledge, 1993.

NUNN, H. "Errol Morris: documentary as psychic drama”. Screen, v. 45, n. 4, winter, 2004.

PAASONEN S. "Analysing pornography". In: IX MAGIS SPRING SCHOOL, Porn Studies Section, Gorizia, Itália, 2010. Mimeografado.

"Labors of love: netporn, Web 2.0 and the meanings of amateurism”. New Media E. Society, v. 12, n. 8, p. 1297-1312, 2010.

SARLO, B. El imperio de los sentimientos: narraciones de circulación periódica en la Argentina (1917-1927). Buenos Aires: Norma, 2000. 
SINGER, B. Melodrama and modernity: early sensational cinema and its contexts. New York: Columbia University Press, 2001.

THOMPSON, K. “The concept of cinematic excess”. In: BAUDRY, L.; COHEN, M. (Orgs.). Film theory and criticism. New York: Oxford University Press, 2004.

TÜRCKE, C. Sociedade excitada: filosofia da sensação. Campinas: Unicamp, 2010.

WILLIAMS, L. "Film bodies: gender, genre and excess". In: BAUDRY, L.; COHEN, M. (Org.). Film theory and criticism. Oxford: Oxford University Press, 2004. Hard Core: power, pleasure and the frenzy of the visible. Berkeley: University of California Press, 1989.

XAVIER, I. O olhar e a cena: melodrama, Hollywood, Cinema Novo, Nelson Rodrigues. São Paulo: Cosac Naify, 2003. 